\title{
'They Eat Potatoes, I Eat Rice': Symbolic Boundary Making and Space in Neighbour Relations
}

\author{
by Gwen van Eijk \\ Leiden University \\ Sociological Research Online, 16 (4) 2 \\ <http://www. socresonline.org.uk/16/4/2.html> \\ $10.5153 /$ sro. 2471
}

Received: 11 Feb 2011 Accepted:21 Sep 2011 Published: 30 Nov 2011

\begin{abstract}
This article examines 'neighbouring' as the setting in which cross-category relations develop and symbolic boundaries are constructed. The study is based on thirty in-depth interviews with residents living in a multiethnic and a mono-ethnic neighbourhood in Rotterdam, the Netherlands. The findings challenge the hopedfor outcomes of social mixing in neighbourhoods, as well as the view that boundary making is something inherent to multi-ethnic neighbourhoods only. Neighbour relations are often setting-specific (relations are interchangeable, scripted and bounded, and passively maintained), which is relevant for understanding the spatiality of neighbouring and the limited exchange of personal information between neighbours. Because neighbouring involves the balancing of personal privacy and close spatial proximity, the exchange of personal information is limited, while spatial proximity ensures easy access to observable (through seeing, hearing and smelling) categorical markers that signify class, ethnicity, lifestyle, etc. In this way, neighbour interaction reconstructs symbolic boundaries rather than breaking them down.
\end{abstract}

\section{Keywords: Boundary Making, Intergroup Contact, Multi-Ethnic Neighbourhoods, Neighbouring, Setting, Space, Symbolic Boundaries}

\section{Introduction}

I: Do you think your neighbours are the same as you, or different?

R: I think they are different. Because I... I think because I'm Antillean. [It's a] different culture. So there's always a difference there, when you have a different culture. I think. Like food, they usually eat potatoes, I [eat] rice. Sometimes [I eat] baked or cooked potatoes but usually rice. So there's a difference there.

1.1 In the above excerpt, a woman living in a multi-ethnic neighbourhood in Rotterdam, the Netherlands, describes to me how her next-door neighbours differ from her. For her, the fact that her neighbours usually eat potatoes while she usually eats rice signals and confirms that they have a different 'culture'. Her neighbours are of Dutch origin, she thinks, while she was born and raised in the Netherlands Antilles. What is interesting about her assessment is that it is based largely on observation. She hardly knows her neighbours: she only talks to them on the street whenever they run into each other. But to know that her neighbours eat potatoes she does not need to know them: she smells it. We often socially identify and categorize others based on observations and 'sign-reading' (Goffman 2007 [1959]; Bourdieu 1984: 243). However, in some situations we rely more on observations than in others. We get to know strangers in the street only through reading and interpreting their appearance, whereas we know much more about our closest friends because they tell us things about themselves. The difference between 'personal' knowing and 'categoric' knowing (Lofland 1973: 15-16) thus relates to interaction forms and the information that is exchanged.

1.2 This article draws on and aims to contribute to studies on neighbouring in mixed neighbourhoods, space, intergroup contact and boundary making, by examining boundary making in neighbour relations and the ways in which neighbouring reconstructs symbolic boundaries. Studies on the 'contact hypothesis' focus on the circumstances under which categorical knowing transforms into personal knowing and show that certain interaction forms can break down categorical thinking and prejudices (Allport 1958; Pettigrew 
1998). According to the 'De-Categorized Contact Model', "'personalization" of the contact situation should lead to a more individuated mode of information processing and, thereby, enhance the potential for group stereotype disconfirmation' (González \& Brown 2003: 196). In Pettigrew's (1998: 76) words, the 'friendship potential' of the contact situation is essential, because it implies 'self-disclosure' and 'extensive and repeated contact in a variety of social contexts'. In such situations, people learn more about each other than a mere categorical identity.

1.3 Studies on cross-category relationships have also focused on multi-ethnic neighbourhoods, echoing the socio-political concern with ethnic mixing and fostering good interethnic relations in multi-ethnic neighbourhoods (Baumann 1996; Blokland 2003a; van der Laan Bouma-Doff 2007; Fortier 2010). In the Netherlands, as in the UK, the preoccupation with interethnic relations should be seen in the light of the proclaimed death of multiculturalism and not just the 'culturalization' but the 'islamization' of social problems (Duyvendak et al., 2009). Following 9/11, 7/7 and the assassination of the Dutch film-maker Theo van Gogh by a Muslim fundamentalist in 2004, many of the concerns about ethnic differences and tensions now focus on the role of Islam in Western society. Furthermore, multi-ethnic neighbourhoods are often depicted as 'problem places' as ethnic mix correlates with social problems (poverty, disorder) and a bad reputation. Neighbour relations in such places are often thought to be dysfunctional or even hostile, which has led to policies aiming to foster 'social cohesion' (Blokland 2003b, Fortier 2010). This makes it particularly relevant to investigate relations and boundary making in a multi-ethnic neighbourhood. There seems to be an understanding that boundary making is inherent to ethnic differences. However, based on a comparison of neighbour relations in a mono-ethnic and a multi-ethnic neighbourhood in Rotterdam, this article challenges that idea by showing that boundary making also happens in other neighbour relations and that it is (also) related to the way in which neighbours interact with each other.

1.4 Furthermore, the article demonstrates why neighbourhoods may not be successful in breaking down categorical boundaries. This article draws attention to neighbouring as the 'setting' (Weber, 2001) that shapes, and is shaped by, interactions. The term 'neighbouring' is here reserved for interactions among immediate neighbours, that is, those who live in adjacent dwellings immediately next, above, below and opposite each other. I will show how the spatiality of neighbouring (Stokoe 2006) and the 'scriptedness' of neighbouring, which involves balancing privacy and proximity, help understand how symbolic boundaries along various lines remain intact. The analysis thus moves away from neighbourhoods as rather large and abstract entities and instead zooms in on the location and situation of neighbour encounters. Furthermore, where contact studies usually focus on the breakdown of boundaries, this article examines how interaction reconstructs boundaries. Both approaches may reach the same conclusion (i.e. symbolic boundary making persists through neighbouring), but contact studies achieve it by identifying that which the neighbourhood is not (i.e. in Pettigrew's words, no friendship potential), whereas I focus on how neighbouring does enable boundary making. Such insights are of equal importance in understanding when and how cross-category interaction may dissolve boundaries (Dixon 2001).

\section{Boundary making, setting-specific interaction and the blurring of boundaries}

\section{Categorization and boundary making}

2.1 In a social-psychological sense, people categorize things in order to make sense of the world around them and they do so by lumping seemingly similar things and splitting seemingly different things (Zerubavel 1996). Categorization goes hand in hand with boundary making. In order to categorize things we need to draw boundaries, make distinctions. To paraphrase Barth (1969: 15), the boundary defines the category, not the stuff that it encloses (cf. Abbott 1995). In understanding experiences of differences, it is essential to know how people draw boundaries. For example, one might say 'I'm working class and my neighbour is middle class'. But what do these categories mean? Perhaps this person will say: 'My neighbour has much more money than I have, you can see it in the way she dresses and how she decorates her house'. So then we know that the way people dress or decorate their houses matters with respect to where this person draws boundaries (and we then would need to further specify what it is about decoration and clothes that signifies a difference, etc.). Thus, to understand perceptions of difference, insight into the process of boundary making tells us more than insight into mere categorization.

2.2 My interest is in symbolic boundaries rather than social boundaries (see, for this distinction, Lamont \& Molnár 2002). Symbolic boundaries are conceptual distinctions, whereas social boundaries are materialized in unequal access or command of resources (ibid.). While symbolic boundaries are necessary for the making of social boundaries, they need not result in social boundaries (e.g. stereotyping can exist without resulting in discrimination). Vice versa, symbolic boundary making may draw on existing social boundaries. They are made and unmade in connection with practices (experiences, in situ) as well as existing categories and boundaries in, for example, organizational and political structures (Wimmer 2007; Tilly 2004). Such existing social boundaries may be 'borrowed' and reproduced in everyday interactions and settings (Tilly 2004).

2.3 While acknowledging that the characteristics of the people involved in the interaction and existing social boundaries matter for symbolic boundary making, here I wish to draw attention to the ways in which the location and situation of interacting co-shape boundaries.

\section{Setting-specific interaction}

2.4 People interact with each other in numerous different ways and such interactions do not evolve in thin air. Rather, people meet and mate in 'settings': 'at work', 'in school', on 'playgrounds', at our 'friend's birthday party' and in our 'neighbourhood'. I use the concept 'setting' (Weber 2001) rather than the often loosely used 'context' to acknowledge that time and space are meaningful in interaction - it is not just 
'background' (Abbott 1997). That is, where, when and how people interact matters for how interactions develop and for interpretations of markers of similarity and difference.

2.5 Setting is an ethnographic 'conceptual tool' and refers to a more or less durable and 'relatively uncrystallized milieu' that ties people and things together through shared definitions of situations and interactions between the people that are shaping the setting (Weber 2001). A setting is not a fixed entity but shaped through interactions. In turn, settings shape interactions:

Above all, the social setting imposes meanings upon the events that take place within it. [...] relationships are themselves qualified by the 'social setting' within which they are actualized: different settings are based on different codes of politeness, different norms of behaviour; they mobilize different emotions, they lead to different native interpretations of the events that take place within them. (Weber 2001: 486-487)

2.6 In other words, this definition moves away from the idea that 'context structures agency' (i.e. enabling or hindering certain actions) to an understanding of how networks of shared definitions co-constitute settings through linking together interactions, interpretations and definitions of interactions, things, places and events. People in turn draw on their experiences and understandings of setting in their interactions with others in the settings, thus reconstructing the setting. In a way, a setting may provide a 'script' for interactions while particular events and experiences provide 'local knowledge' which makes actual interactions variable within the 'frame' of the setting (cf. Tilly 2005: 81ff).

2.7 Many of the interactions with people we meet in our everyday lives occur only or mainly in certain settings. Put differently, many relations with others are 'setting-specific': they are maintained in the setting where people originally met each other (Allan 1998). We meet colleagues mostly at work, fellow club members at club meetings and fellow residents in our neighbourhood. This has become even more so in recent decades, because different life domains have become less integrated and thus networks have become more compartmental or non-overlapping (Simmel 1955 [1922]; Blokland \& Rae 2008; Wellman 2000 ). With only a few of the people we meet in these settings do we develop 'setting-exceeding' relationships: they become relationships that are maintained in other settings, next to or instead of the setting in which we originally met each other (Allan, 1998). We are more likely to label such relationships as 'friendships' or 'acquaintanceships' - labels that say nothing about the situation or location in which people socialize, as opposed to the more concrete labels that we use to describe more bounded relationships: 'colleagues', 'club members', 'neighbours'.

2.8 The distinction between setting-specific and setting-exceeding ties matters for understanding the processes of making and unmaking boundaries. Intergroup contact theory identifies several conditions under which de-categorization may occur. The 'right' conditions (Pettigrew's criteria of 'friendship potential') change the nature of the relationship: the people involved know more about each other because they exchange more and a wider range of information about each other. In order to move from inter-categorical to interpersonal interaction we need personal information; personal information initiates the process of decategorization (Tajfel 1982; Pettigrew 1998). Setting-exceeding and setting-specific relations differ in the quantity and nature of information we receive about others. Interactions with the cashier will often reveal little about his personal life - does he have a family, is he religious, where does he live? That is, unless the cashier is very chatty with other cashiers and we, as regular customers, overhear their conversations. This information may, however, often be rather without context: we overhear and see things which we then have to interpret ourselves. When we have little personal information we are more likely to draw on available categories and ascribe stereotypical identities to others (Blokland 2003b). Categorization easily leads to stereotyping and enhances group thinking and boundary making (Fiske \& Russell 2010). In this way, when little information is deliberately exchanged but at the same time some information is 'unwittingly' received, interaction does not necessarily break down perceptions of difference or symbolic boundaries. Thus, under certain conditions, interaction may rather reconstruct symbolic boundaries (see e.g. Blokland 2003a; Graves 2010).

\section{Neighbours as setting-specific relations}

2.9 Many neighbour relations are setting-specific relations, as I will substantiate more elaborately below. It would be quite easy to establish that interaction between neighbours does not occur under Allport's and Pettigrew's 'right' conditions. For example, residents rarely work cooperatively towards a common goal. An exception is, perhaps, those involved in a homeowners' association or residents' organization, but then such institutions may be segregated along the lines of class, ethnic background and age when they fail to represent the population diversity, thus not fostering cross-category interaction. Cooperation in a mixed neighbourhood may be absent, particularly when different residential categories have different needs and ideas about liveability and safety (Smith 1996; Mitchell 2003; Pattillo 2009). Furthermore, again particularly in a mixed neighbourhood, residents do not necessarily perceive themselves as having an equal status (Blokland 2003a). Finally, there is often no authority structuring their interaction (management enforcing good neighbouring might even discourage cross-category interaction, see Graves 2010).

2.10 But this leaves the question of how neighbouring does reproduce symbolic boundaries. Based on various studies on neighbouring and my own study on neighbour relations, I argue that there is something particular about neighbouring that makes the breakdown of categorical boundaries difficult, even when neighbours interact and get along fine. This is not to say that the neighbourhood is particularly special. Other settings may similarly reproduce boundaries. Work relations, for example, are often intertwined with hierarchies and power relations, which are likely to reconstruct symbolic boundaries. Similarly, certain elements of neighbouring seem to contribute to boundary making. Intergroup contact theory acknowledges the situational variations of interactions but it is not grounded in any space - interaction could happen 
anywhere. Furthermore, little attention has been paid to the scripted nature of setting-specific relations. Yet, what is specific for neighbouring is the spatiality and scripted nature of interactions. The following sections are dedicated to demonstrating how this relates to, and reproduces, boundary making. First I discuss the study.

\section{The study}

3.1 This article is based on a larger study on the relation between neighbourhood composition and the formation of personal networks (van Eijk, 2010). I draw on thirty in-depth interviews with residents of two neighbourhoods in Rotterdam (the second largest city in the Netherlands): Hillesluis, a multi-ethnic and relatively deprived neighbourhood, and Blijdorp, a mono-ethnic (white Western) and relatively affluent neighbourhood. ${ }^{[1]}$ The value of analysing neighbour relations and boundary making in two differently composed neighbourhoods is that it prevents putting too much emphasis on a particular kind of boundary. This comparison illuminates not only differences, but also similarities in the ways in which boundaries are constructed.

3.2 The interviews followed an initial survey interview that aimed to map respondents' personal networks. In this article I focus solely on the data about networks that members reported and labelled as 'neighbours'. Nearly 90 per cent of the respondents of the survey $(n=195)$ had reported at least one neighbour. In the second interview, we talked about reported neighbours as well as about direct neighbours that the respondents had not mentioned. The survey had already gathered information about perceptions of difference and sameness in terms of 'membership of ethnic or national group' and 'place in a class scheme'. In the follow-up interview, I wanted to know more about such perceptions of difference and sameness. However, unlike the survey, I did not want to restrict such perceptions to class and ethnicity. So I started out by asking respondents a more open question: 'Do you think you and your neighbour are different/similar, if so, how?' I questioned markers of difference and sameness, in order to gain insight into respondents' interpretations of (observable) markers. I asked separate questions about class and ethnicity. Thus, the excerpts included in the analysis for this article come from different parts of the interviews.

3.3 All interviews were recorded, transcribed and coded (using software MAXQDA). For this article I selected all segments in which respondents talk about their neighbours - those reported as network members and those who live next-door, above or below them. Many respondents live in low-rise walk-up flats - with shared entries and stairs - consisting of six apartments and thus have five neighbours. I asked for descriptions about all neighbours and would usually talk about one or two neighbours in more detail. All names in this article are fictitious. In parentheses following each excerpt is the respondent's neighbourhood ( $\mathrm{BD}=$ Blijdorp, HS=Hillesluis).

\section{Neighbouring as setting-specific interaction}

4.1 While any relationship form can develop between fellow residents - mere geographic proximity does not define the type of relationship (Blokland 2003b: 80) - in practice we see more of some forms than others. Neighbour relations may occur in four forms (ibid.: 66f). First, in urban areas neighbours can hardly avoid each other, so there is at least a relation of 'interdependency'. Interdependencies are abstract relations through which people know of each other but little about each other: little personal information is (deliberately) exchanged. Second, neighbour relations occur as 'transactions' in which small exchanges of support occur, such as watering the plants or exchanging keys for emergency situations. Third, in 'attachments' neighbours interact because they value 'good neighbourly relations' (ibid.: 80) which means being friendly and helpful while respecting each others' privacy. Fourth, neighbour relations occur as 'bonds' where people maintain a friendship or friend-like relationship with each other.

4.2 In my research, I found all four forms. Yet interdependencies, transactions and attachments are much more prevalent than bonds. When neighbour relations are characterized by that which we often call 'neighbouring', we usually mean a specific pattern of interaction revolving around transactions and attachment (Abrams \& Bulmer, 1986; Buonfino \& Hilder, 2006; Crow et al., 2002; Kusenbach, 2008; Mann, 1954). Several characteristics of neighbouring - interchangeability, scripted nature and passiveness illustrate the setting-specificity of neighbouring and are relevant in understanding how boundaries are reproduced.

\section{Interchangeability}

4.3 Whereas in bonds the 'uniqueness of individuals' (Blokland, 2003b: 83) matters, it does not for the three most prevalent forms of neighbour relations in which neighbours are rather interchangeable. Interchangeability is the first way in which the setting-specificity of neighbour relations is exemplified. Many neighbour relations break when one of the two moves away. For example, one respondent explained that she was very fond of her neighbour because he was friendly and considerate, but after he moved away they did not keep in touch, because 'we were in touch just because he was a neighbour, now we have new neighbours' (BD). Many of the neighbour relations take on one of the three other forms and thus are not based on affective feelings for each other (people may be friendly but not friends). Often, neighbours were described as 'just neighbours':

I: Are you still in touch [with former neighbour]?

R: No, yes, we do greet each other ... when we see each other then we do have a chat.

$\mathrm{I}$ : Are you neighbours or friends?

R: No just neighbours. (BD)

I: From where do you know [neighbour] and [neighbour]? 
I: How do you know [neighbours]?

R: Well they're just neighbours; we have a chat now and then. (HS)

4.4 'Just' emphasizes the ordinariness of the relationship as being not special. That a respondent has known the neighbour for a long time or is very fond of the neighbour does not necessarily mean that the relationship becomes more than 'just neighbours':

I: What is [neighbour] like?

R: Really a super neighbour and a really nice person. Not really a friend I would say but ... You know what they say: better a good neighbour than a distant friend, well this is such a neighbour. (BD)

I: How long have you known [neighbour]?

R: All my life, so to speak. [We have] normal contact, like neighbours. (HS)

Longevity and affectivity thus do not automatically transform neighbour relations into friend-like relationships. Rather, 'neighbour' seems to be a label for a specific kind of relationship.

\section{Scripted and bounded exchanges}

4.5 What constitutes this specific relationship? People seem to have a clear idea about that which 'good' neighbouring involves and that which a neighbour should and should not do. Studies have shown that, for many, friendliness, helpfulness and respect for privacy are essential elements of positive neighbouring (Abrams \& Bulmer 1986: 30) and that good neighbouring 'lies in maintaining the tension between cooperation and privacy, helpfulness and non-interference, between friendliness and distance' (Allan, 1983, cited in Buonfino \& Hilder 2006: 13; cf. Crow et al. 2002; Blokland 2003b).

4.6 There thus seems to be a 'script' for neighbour-to-neighbour interaction that involves certain forms of support but not others: the kinds of support that do not require too much personal involvement. According to the script, exchanges are limited and signify the bounded nature of the relationship. This is first manifest in the mentioning of 'typical' things that neighbours do for each other: taking care of plants, mail and pets during holidays, exchanging keys, borrowing food items or tools, offering support in cases of emergency (Blokland 2003b; Kusenbach 2008; Wellman \& Wortley 1990; Völker \& Flap 2007; Abrams \& Bulmer 1986; Crow et al. 2002). Exchanging keys, for example, does require a certain level of trust in each other - trust that the neighbour will not enter the house - but at the same time it does not demand any actions from the key holder other than to hold on to the key. The bounded nature of the exchanges is further exemplified by respondents mentioning interactions that did not take place: 'we get along but we don't visit each other' or 'we'll have a chat, but that's it'.

\section{Passiveness}

4.7 Finally, a third expression of setting-specificity involves the passiveness of neighbour relations. The script of neighbouring often involves 'latent' or 'reactive' neighbouring rather than 'manifest' or 'proactive' support (Mann 1954; Abrams \& Bulmer 1986; Kusenbach 2008). The latency of support is intertwined with the given nature and geographical proximity of neighbours: they are not chosen relationships so there are no or limited expectations of the relationship evolving towards friendship or frequent exchanges. Yet, since they are there, they make for very suitable support ties, but only if necessary and with reasonable demands - this harks back to the scripted bounded nature of neighbouring.

4.8 That which signifies passiveness is that much neighbour interaction depends on external factors. Respondents explained that interactions depended on external factors (rather than their own choosing to interact) such as the weather and season and the built environment. The interviews were held during the winter and early spring and some respondents said that neighbouring was different then, because everybody comes home in the dark and gets inside quickly because of the cold and rain, than in the summertime. Building design matters to the extent to which and how often people run into each other. One respondent had moved-in between the first and second interviews and she reflected on the difference in interacting with her neighbours. In her old apartment she was used to having many opportunities to interact with her neighbour because their doors bordered each other and they could see each other through the windows from their living rooms (they used to wave to each other and make frequent eye contact). But in her new apartment building, which is star shaped, things are different:

I: Have you made contact yet with your neighbours?

R: Not so much. Next-door, I've seen her a couple of times, and on the other side that man I've seen five times. You come up [the stairs] here, you live in this area, you watch over that street over there, but your neighbours go around there. [...] You see each other very little. (BD)

By noting these factors, respondents show how much interaction is based on mere proximity rather than choice or personal affection. People are often not very proactive in building relationships with their neighbours but let much depend on chance encounters.

4.9 Thus we can see multiple ways in which people together, through interacting, construct and reconstruct a setting that involves narrowly defined exchanges and expectations. What is more, neighbouring as a setting is strongly linked and bounded to particular physical spaces. 


\section{The spatiality of neighbouring: balancing privacy and proximity}

5.1 Neighbouring is not only limited in that which can and cannot be exchanged - it is also bounded in space. The spatiality of neighbour interactions (Stokoe 2006) means that interaction takes place mainly outside the home and in shared spaces such as hallways and stairs. Interaction, further, often revolves around boundaries between homes such as walls (e.g. in the case of nuisance) and fences (e.g. in the case of maintaining hedges). Such boundaries, as well as the (often unclear) geographically bounded space of the 'imagined' neighbourhood, are frequent topics of conversation. The following excerpts exemplify the spatiality of neighbouring:

I: Do you visit each other?

$\mathrm{R}$ : No, no visiting. But we do have a regular chat, yes, in front of the door. (HS)

I: What's your contact like?

R: Well just outside, just a chat. (HS)

I: What kind of people are your neighbours?

R: Far in their 70s. Just, well, we know each other, but they're also whiners when it comes to how high the trees are and how clean you keep everything. (BD)

I: Are you in touch with your neighbours?

$\mathrm{R}$ : Yes just contact through the homeowner's association, when things need replacing, sagged tiles. (BD)

I: Did you ever help each other out with something?

R: Oh yes, yes, for example with the garden, back then, with carrying bags inside, cleaning the street and those kind of things, then you help each other, and [my father and neighbour] always do the hedge, [neighbour] does sort of from the top all the way so that my father only has to do the side. (HS)

5.2 When relations between neighbours do transform from neighbouring into a friend-like relationship or friendship, the exchange of support and the spatiality of the relationship change. For example, one respondent described her relationship with her neighbour as being 'good friends':

I: What do you share with each other?

R: All sorts of things, when she has problems she tells me, or if I have a problem I tell her. When she goes away she gives me her key, those things, just like two sisters who share all sorts of things with each other, and laughing [together], we just support each other. [...] Yes, and just recently they helped here in the house, painting, such a lot, weeks on end they were here from the morning on and then working all day to help. (HS)

5.3 We could argue that where two neighbours become friends, the setting of the micro-neighbourhood does not matter anymore: the setting ceases to exist and is replaced by a new setting ('friendship'?) that transcends the limited geographical space. Thus, the spatiality of neighbour relations is typical of the forms of interaction that are most prevalent among people who live next to each other (i.e. interdependency, attachment and transaction, see above).

5.4 The spatiality and scripted nature of neighbour relations are bound up with the (unchosen) spatial proximity of neighbours and the need for privacy in one's home that follows from this proximity. So, while settings need not be located in a particular place, in the case of neighbouring space it is very relevant because the scripted nature of neighbouring is linked to geographical boundaries. Moreover, the spaces in which most neighbouring takes place are 'strongly classified places' in which that which is 'inside' and that which is 'outside' are clear, as opposed to weakly classified places where these categories and boundaries are less or not clear (Sibley 1995: 80). Doors, walls and fences signify not only spatial boundaries, but also norms of privacy, which is even more important given the unchosen proximity between neighbours. It is very clear which spaces are private (home) and which are not ('outside'), and such distinctions are constantly signified in and through neighbour interactions. Importantly, strongly classified places may strengthen symbolic and social boundaries by emphasizing the insider-outsider distinction and by eroding personal exchanges (Sibley 1995). The spatiality of neighbouring practices, following from and constructing the need to balance proximity and privacy, may thus strengthen symbolic boundary making.

\section{Categoric knowing: exchanging and observing information}

\section{Familiarity and observation}

6.1 So, how are the spatiality of neighbouring and symbolic boundary making connected? First of all, we need information about others in order to draw boundaries and categorize others as 'alike' or 'different' (Merton \& Rossi 1968; Blokland 2003b). The kind of information we gain and how we gain it is related to the type of interactions and our position in relation to others on the 'privacy continuum': the amount of control we have over disclosing personal information (Blokland 2003b: 91). In anonymous relations 'people act without supplying personal information beyond what is superficial or strictly necessary to facilitate the operation', whereas in intimate relations 'people exchange a large amount of personal information' (ibid.). Between these extremes there can be 'familiarity' through which people 'know enough about each other to establish their respective social positions' (ibid.). In Lofland's (1973: 15-16) words, where intimacy would result in 'personal knowing', familiarity would result in 'categoric knowing'. 
6.2 Neighbours are usually familiar with each other rather than anonymous or intimate, although how familiar they are with each other varies. As we have seen, neighbour relations, in the form of interdependencies, attachments and transactions, often exist only in public (street) or semi-public (stairway) places: they are linked to bounded spaces (outside but near the home) and often depend on chance encounters (as opposed to deliberate efforts to interact). This is relevant because access to information through familiarity is highly dependent on visibility (Blokland 2003b). However, and this is how neighbour relations differ from encounters with strangers, we also have access to information when there is no immediate interaction: we might hear our neighbours through the walls or outside in their garden, we might smell their food and we see their curtains and how well they keep their garden. Neighbours often receive limited first-hand information about each other but also receive much information mainly through observation.

6.3 Having some information, but not really knowing, is characteristic for neighbour relations. Respondents often emphasized that they did not know or were not sure about things (cf. Stokoe, 2006). On the one hand this signifies their limited knowledge. On the other, respondents may feel the need to emphasize their lack of knowledge because the norm is to 'keep oneself to oneself' and not intrude into each other's personal lives (ibid.). But it is impossible not to observe (see, hear, smell) things that say something about how neighbours live their lives.

I: The neighbour next-door, you [said you] don't know that much about him, but when you see him, could you classify him, can you assess [his place in a class scheme]?

R: I think lower class, because he had bailiffs coming to his door a couple of times, so I don't think he has much, but well, I don't know. (HS)

I: What kind of people are they?

R: They are Turkish people, also well, yes, difficult to say but I think also our age, a little bit older. (HS)

I: Can you tell me something about your neighbours?

$\mathrm{R}$ : A little, a little. Below, they have been living here for quite some time, an older couple from East Turkey, they're here in the winter only, in the summer they go to Turkey, their sons and grandsons collect their mail, I know them a little too, one is a conductor on a tram, I see him once in a while, too. Opposite them, I don't know them, I just know they always have shoes outside their door. [...] Upstairs from me [lives] a Moroccan [man], [I've] seen him twice, I just know his aftershave is horrible. Upstairs opposite, [a] Moroccan girl, head scarf but quite sociable, we have a chat now and then. (HS)

I: Do you know what kind of people they are, do you know them at all?

R: No, I know, when I see them, if I run into them, the only thing that we say to each other is good day, good morning but it's not like we ask each other, we do hear through others who they are.

I: So who are they?

$\mathrm{R}$ : Next-door it is Moroccan, next to them is Turkish, here [other side next-door] is a Dutch woman and opposite from here I think they are Surinamese people when I just look at them and there [next to them] lives an elderly Dutch lady and she waves to me now and then and then I always wave back and that's it really. (HS)

6.4 Information is thus limited but accessible. Respondents gained some of the information not through immediate personal encounters but through observing things that they just 'happen' to see, hear or smell because of the close spatial proximity of the homes. The first respondent had never discussed the visit of the bailiffs with her neighbour because they never talked to each other - she did not like him at all. The second respondent apparently never asked about the exact age of her neighbours, while the third respondent also never talks to one of his neighbours but sees shoes in front of the door. The fourth respondent, finally, does not know her neighbours but is, nonetheless, able to describe their (alleged) ethnic identities.

6.5 What is important for boundary making is not only that information is observable but also that it is without context: people mostly interpret all this without getting much direct information from the people they observe. Put differently, while all this information is seen, heard and smelled, there is often no opportunity for people to hear the full story, to understand the context of their observations. They would not know why their neighbour has financial problems (respondent's interpretation of the bailiff visiting) or why neighbours leave their shoes outside (customs or mysophobia?). Whereas in the case of friendships we would know why people do this and have a better understanding of whether and how this relates to aspects of 'culture', 'class' or 'lifestyle', in the case of neighbours we cannot ask - asking would transgress the norm of privacy - and thus we are left to guess. A lot of the information people have about their neighbours is based on observations and then interpretations and guesses:

$\mathrm{I}$ : What kind of man is he?

R: Well what kind of man is he... An alcoholic, there's a lot the matter with him, he does work I think or he's in the pub all day, I don't know exactly, but for the rest you never see him really, I never hear him really, so. Every time when I run into him there's a smell [of alcohol] coming off him like, I go like wooooow. (HS)

I: The next-door neighbours, do you think they have a similar lifestyle as you do? R: Well I wouldn't dare to judge that. Well, it would be sort of the same, I'm not bothered by any noise, at least it's not their hobby to turn the music really loud. No but well, my 


\section{Interpreting markers: drawing (ethnic) boundaries}

6.6 People's guesses are however not random. Boundary making and categorization in everyday situations is often linked to existing and known categories (borrowing, Tilly 2004). With limited personal information to 'explain' observable markers, people tend to rely on available categories and boundaries and more easily ascribe stereotypical identities to others (Fiske \& Russell, 2010). In such situations, when others look different people easily assume that they are different (Blokland 2003b: 80, 214). This might explain how fairly superficial markers become interpreted as 'cultural' differences.

I: Do you think you and your neighbours are different?

R: Yes it's quite possible we are, because they have a different culture. I also have a different culture so it's quite possible that that's different.

I: And can you see that, that they have a different culture?

R: Yes, their clothing. That woman wears a headscarf. Because I know from Turkish people that they have a different culture, so that's why I can say that. (HS)

I: How do you think you and your neighbours are different?

R: Well that would be a bit of a cultural difference. They have their norms, Turkish norms I do think, norms and values, quite a conservative identity I think.

I: How does that manifest itself?

$\mathrm{R}$ : She wears a headscarf, well not always in the house. Sometimes, rarely also outside she doesn't, I guess she forgot. But you do see that they try to avow to that. But for the rest they are just normal ordinary people. (HS)

I: The neighbours next-door, an Indian family you said, do you have things in common? R: No. I think that, [we have a] very different culture. You could tell, they arrived over a period, he arrived earlier than she did, it was extremely cold at the time. Everything tightly shut, curtains, and then you saw them on the street, well, of course, they're not used to these temperatures. I get the feeling that she stays inside quite a lot, [she] also doesn't speak the [Dutch] language. He goes to work every day. For the rest I don't know them. [...] I: So you immediately said "the culture is different", how is it different?

R: Well I'm not religious or nothing... And... When you see those two together then she has a subordinate role to him. But that's maybe also because he's been here [in the Netherlands] longer. I don't know them well enough to further answer that question. (BD)

6.7 In the first two excerpts, respondents rely on clothing to assess whether their neighbours are alike or different and the grounds for such differences. Both respondents refer to the headscarf of their neighbour which is something that is easily observable, even without immediate interaction, and which many native Dutch people would take as something that is linked to non-Western societies, as few Dutch women, except for a few elderly women perhaps, wear headscarves. Yet, respondents did not only conclude that their country of origin is different, they assume that their 'culture' is different. The first respondent does not clarify what she means by culture but the second respondent does by talking about 'norms and values' and a 'conservative identity'. The respondent could have interpreted his observation that the neighbour sometimes 'forgets' her headscarf as a sign that they are quite progressive. However, that he interpreted the headscarf as conservative may signal that, first, the respondent has little knowledge of variations among Muslims, and second, that he relies also on the available categorical identities of non-Western minorities as religious and conservative. Such ideas are pervasive in political and social debates and in media coverage, particularly in the last decade (D'Haenens \& Bink 2007), about, for example, whether or not to abolish the headscarf form public spaces (Shadid \& van Koningsveld 2005). As the respondent does not know his neighbours that well, his assessment is grounded in a rather simplified image of Muslim women.

6.8 The third respondent also seems to draw on such available images of non-Western 'culture' in terms of more traditional gender roles which she sees confirmed in the woman's 'subordination' to her partner and the fact that she stays in the house a lot. She also hints at religion, assuming that her neighbours are religious while she is not. Here, the respondent does leave room for an alternative interpretation: the woman has not been in the Netherlands as long as her partner. The respondent is thus not sure but she interprets various markers as signs of 'cultural' difference.

6.9 Nevertheless, even if respondents cannot be absolutely sure, they are quick to draw boundaries based on 'culture'. All three respondents respond to an open question about differences and mention 'culture' first. This signifies the dominance of 'culture' over any other categorical characteristic in relation to 'difference' in the Netherlands and echoes the preoccupation with ethnic differences, and Islam in particular, in sociopolitical discourse. Not surprisingly, boundary making along lines of ethnicity - or 'culture' as most respondents put it - is more prevalent in the interviews with respondents living in Hillesluis (the multi-ethnic neighbourhood), compared with the interviews with respondents living in mono-ethnic Blijdorp.

6.10 However, this should not be taken as an indication that there is something particular about different ethnic origins that makes boundary making more likely in neighbour relations in multi-ethnic neighbourhoods. That is, it is not only due to the different ethnic origins of neighbours that categorical boundaries were drawn. Respondents in the ethnically homogeneous neighbourhood Blijdorp also drew boundaries and interpreted observable markers in order to assess differences or similarities. More often, however, their assessments were based on age and household compositions, which were interpreted as generational, life stage and lifestyle differences. 
I: How are you different, do you think?

$\mathrm{R}$ : Well, another generation.

$\mathrm{I}:$ Can you notice that in your interaction?

$\mathrm{R}$ : Yes, well, look these are rather noisy houses. I always think, you hear people walking and sometimes music, where people live you're bound to hear that but for them that's awful, they think it's horrible that they have to hear all this. I think, well, tomorrow it's you, the day after [it's] me, well that's just how it is, it's not an old people's home of course. They find that difficult sometimes. Also the fact that, in the old days they cleaned twice a week, every housewife cleaned her own doors. That just doesn't happen [now]. People work nowadays. [...] For them it's not what it used to be, but that's just the times. (BD)

I: The people below, do they have a bit of a similar lifestyle as you do?

R: A moody couple. Well, [they have] two kids, right. I think they go to bed at seven o'clock in the evening. Really very early. I think children do really wear you out. At seven it is really totally dark downstairs. He combines study and work. She, I think she works. I don't hear her that often during the day. I'm at home often during the day. [...] You know things about each other, but that's not really because you hang out with each other often. (BD)

6.11 In the first excerpt, the respondent interprets their differing views on noise and cleaning (together with the apparent age difference and divergent daily activities) as a generational difference - not just as a difference in views on the matter (while we could imagine younger people also valuing silence and cleanliness). Similarly, the second respondent takes the difference in lifestyle as a consequence of having or not having children (while we could imagine people with children who do have a more active nightlife, and perhaps it's not the children but other things going on). Thus, residents of a mono-ethnic neighbourhood may also construct symbolic boundaries, which are, as in the multi-ethnic neighbourhood, at least in part grounded in the limited but observable information that is exchanged in spatialized and scripted neighbour interactions.

\section{Conclusion}

7.1 Despite the potential for frequent interaction, maintaining neighbour relations often does not mean that categoric knowing transforms into personal knowing, or that symbolic boundaries are dissolved. In other words, instead of seeing their neighbours as 'unique individuals', people tend to ascribe categorical (and sometimes stereotypical) identities to their neighbours. I have argued that it is the interactional form of 'neighbouring' and the setting that it constructs, which in turn shapes relations, that helps understand how symbolic boundaries are reconstructed. The need for privacy - a norm of good neighbouring - means that people are reluctant to share personal information, while at the same time the spatial proximity ensures that categorical markers are easily observed, even when there is no immediate personal interaction. It is this combination of the scripted nature and spatiality of neighbouring that is relevant for understanding the process of symbolic boundary making among next-door neighbours. The particular setting offers little opportunity for personal knowing while at the same time fosters categoric knowing. It is in this way that neighbouring is often related to boundary making, rather than the breakdown of boundaries.

7.2 In this article, I have examined the setting of the micro-neighbourhood. My call for zooming in on the setting and the setting-specificity of interactions may, however, have a broader relevance. The reconstruction of symbolic boundaries may work out differently in similar settings in different countries (where different norms of 'good neighbouring' might apply) and in different settings such as the work place, school, public spaces, leisure clubs and political bodies. Further research on different settings would yield valuable insights into how cross-categorical relationships develop and when they involve boundary making or the breaking down of boundaries.

7.3 This is not to say that boundary making is inherently and always a bad thing which will inevitably lead to contentious relations. Neighbours may be perfectly able to allow for differences exactly because of the unchosen nature and scripted nature of neighbouring: one does not need, and often does not desire, to develop more intimate relations with neighbours and thus sameness is less important as long as the norms of 'good neighbouring' are respected. This is also relevant for policies in multi-ethnic or otherwise mixed areas or institutions: the drawing of boundaries does not necessarily equal hostility or conflict. Whether boundaries go beyond mere conceptual distinctions is a question that demands empirical research. Such studies would need to carefully distinguish symbolic boundaries from social boundaries (Lamont \& Molnár 2002): 'mere' boundary making and categorization need not constitute or result in social segregation or contentious relations. Thus, it is important to acknowledge boundary making that allows for differences as well as boundary making that denies differences and results in intolerant prejudices.

7.4 Finally, as I have aimed to show, boundary making among neighbours is not a phenomenon or 'problem' that is inherent to multi-ethnic neighbourhoods or interethnic relations. Ethnic boundary making is problematic because ethnic origin and 'culture' are not necessarily accurate markers in assessing difference and similarity. Age, household form and life stage likely provide more accurate markers. Furthermore, ethnic boundary making is problematic when 'culture' comes to overshadow similarities along other lines. When 'culture' is also seen as a 'fundamental' difference or fixed boundary, such boundaries may be more worrisome because they are likely to be more persistent. However, that ethnic boundaries are interpreted as fundamental or fixed may be grounded not so much in interethnic interactions or in the ethnic attributes of people, but rather in the images that are reproduced in social and political debates and through media coverage. Lacking more detailed information, people tend to draw on widely agreed upon and available categories. Neighbours usually have little access to contextualized information about ethnicity and culture and other things that may matter and, thus, such relations provide a poor basis for correcting such images. In other words, the micro-neighbourhood, as a strongly classified space, and neighbouring, 


\section{Notes}

${ }^{1}$ In Hillesluis, 66 per cent of the residents are non-Western, first and second generation immigrants, mainly from Turkey, Surinam and Morocco. Twenty-eight per cent of the residents have an income below the standard poverty line, while 29 per cent receive unemployment benefits. (Source: Centre for Research and Statistics, Rotterdam, 2005, 2007.) In Blijdorp, 78 per cent of the residents are of Dutch origin, while half of the non-Dutch are Western, first and second generation immigrants. Seven per cent have an income below the standard poverty line, while 28 per cent have an income falling into the highest quintile of incomes in the Netherlands. Five per cent receive unemployment benefits. For reference, the averages for Rotterdam are: 17 per cent below the poverty line, 15 per cent in the highest quintile of incomes, 17 per cent receive unemployment benefits, 54 per cent are native Dutch and 38 per cent non-Western, first and second generation immigrants.

\section{Acknowledgements}

The author wishes to thank two anonymous reviewers for their helpful suggestions. The fieldwork for this article was funded by the OTB Research Institute for the Built Environment, Delft University of Technology. The article was written while the author received a personal grant from the Niels Stensen Foundation.

\section{References}

ABBOTT, A (1995) 'Things of Boundaries', Social Research, vol. 62, no. 4, pp. 857-882.

ABBOTT, A (1997) 'Of Time and Space: The Contemporary Relevance of the Chicago School', Social Forces, vol. 75, no. 4, pp. 1149-1182.

ABRAMS, P, and BULMER, M (1986) Neighbours. The Work of Philip Abrams. Cambridge; NY: Cambridge University Press.

ALLAN, G (1998) 'Friendship, Sociology and Social Structure', Journal of Social and Personal Relationships, vol. 15, no. 5, pp. 685-702. [doi:://dx.doi.org/10.1177/0265407598155007]

ALLPORT, G W (1958) The Nature of Prejudice. Garden City, NY: Doubleday Anchor Books.

BARTH, F (1969) Ethnic Groups and Boundaries. The Social Organization of Culture Difference. Boston: Little, Brown and Company.

BAUMANN, G (1996) Contesting Culture: Discourses of Identity in Multi-ethnic

London. Cambridge: Cambridge University Press.

BLOKLAND, T (2003a) 'Ethnic Complexity: Routes to Discriminatory Repertoires in an Inner-city Neighbourhood', Ethnic and Racial Studies, vol. 26, no. 1, pp. 1-24.

[doi:://dx.doi.org/10.1080/01419870022000025252]

BLOKLAND, T (2003b) Urban Bonds. Social Relationships in an Inner City Neighbourhood. Cambridge, UK: Polity Press.

BLOKLAND, T and RAE, D (2008) 'The End to Urbanism: How the Changing Spatial Structure of Cities Affected its Social Capital Potentials.' In Blokland, T and Savage, M (Eds.) Networked Urbanism. Social Capital in the City, Aldershot: Ashgate, pp. 23-40.

BOURDIEU, P (1984) Distinction. A Social Critique on the Judgment of Taste. Cambridge: Harvard University Press.

BUONFINO, A and HILDER, P (2006) Neighbouring in Contemporary Britain. York: Joseph Rowntree Foundation.

CROW, G, ALLAN, G and SUMMERS, M (2002) 'Neither Busybodies nor Nobodies: Managing Proximity and Distance in Neighbourly Relations', Sociology, vol. 36, no. 1, pp. 127-145. [doi:://dx.doi.org/10.1177/0038038502036001007]

D'HAENENS, L and BINK, S (2007) 'Islam in the Dutch Press: With Special Attention to the Algemeen Dagblad', Media, Culture \& Society, vol. 29, no. 1, pp. 135-149.

[doi:://dx.doi.org/10.1177/0163443706072002]

DIXON, J (2001) 'Contact and Boundaries: 'Locating' the Social Psychology of Intergroup Relations', Theory \& Psychology, vol. 11, no. 5, pp. 587-608.

DUYVENDAK, J W, HENDRIKS, F, and VAN NIEKERK, M (Eds.) (2009) City in Sight: Dutch Dealings with Urban Change. Amsterdam: Amsterdam University Press. 
FISKE, S T and A M Russell (2010) 'Cognitive Processes.' In J.F. Dovidio, M. Hewstone, P. Glick and V.M Esses (Eds.) The SAGE Handbook of Prejudice, Stereotyping and Discrimination, London: Sage Publications, pp. 115-130.

FORTIER, A-M (2010) 'Proximity by Design? Affective Citizenship and the Management of Unease', Citizenship Studies, vol. 14, no. 1, pp. 17-30. [doi:://dx.doi.org/10.1080/13621020903466258]

GOFFMAN, E (2007 [1959]) The Presentation of Self in Everyday Life. London: Penguin Books.

GONZÁLEZ, R, and BROWN, R (2003) 'Generalization of Positive Attitude as a Function of Subgroup and Superordinate Group Identifications in Intergroup Contact', European Journal of Social Psychology, vol. 33, no. 2, pp. 195-214. [doi:://dx.doi.org/10.1002/ejsp.140]

GRAVES, E M (2010) The Structuring of Urban Life in a Mixed-Income Housing "Community"', City \& Community, vol. 9, no. 1, pp. 109-131.

KUSENBACH, M (2008) 'A Hierarchy of Urban Communities: Observations on the Nested Character of Place', City \& Community, vol. 7, no. 3, pp. 225-249. [doi:://dx.doi.org/10.1111/j.1540-6040.2008.00259.x]

LAMONT, M and MOLNÁR, V (2002) 'The Study of Boundaries in the Social Sciences', Annual Review of Sociology, vol. 28, pp. 167-195.

LOFLAND, L H (1973) A World of Strangers: Order and Action in Urban Public Space. New York: Basic Books.

MANN, P H (1954) The Concept of Neighborliness', American Journal of Sociology, vol. 60, no. 2, pp. 163 -168 . [doi:://dx.doi.org/10.1086/221507]

MERTON, R K and ROSSI, A S (1968) Contributions to the Theory of Reference Group Behavior. In Merton, R. K. (Ed.) Social Theory and Social Structure, New York: The Free Press.

MITCHELL, D (2003) The Right to the City. Social Justice and the Fight for Public Space. New York/London: The Guilford Press.

PATTILLO, M (2009) Investing in Poor Black Neighborhoods "As Is". In Turner, M. A., Popkin, S. J., and Rawlings, L. (Eds) Public Housing and the Legacy of Segregation, Washington: The Urban Institute Press.

PETTIGREW, T F (1998) 'Intergroup Contact Theory', Annual Review of Psychology, vol. 49, no. 1, pp. 65 -85. [doi:://dx.doi.org/10.1146/annurev.psych.49.1.65]

SHADID, W and VAN KONINGSVELD, P S (2005) 'Muslim Dress in Europe: Debates on the Headscarf', Journal of Islamic Studies, vol. 16, no. 1, pp. 35-61. [doi:://dx.doi.org/10.1093/jis/16.1.35]

SIBLEY, D (1995) Geographies of Exclusion: Society and Difference in the West. London: Routledge.

SIMMEL, G (1955 [1922]) The Web of Group-affiliations New York: The Free Press.

SMITH, N (1996) The New Urban Frontier: Gentrification and the Revanchist City. London; New York: Routledge.

STOKOE, E (2006) 'Public Intimacy in Neighbour Relationships and Complaints', Sociological Research Online, vol. 11, no. 3, <http://www.socresonline.org.uk/11/3/stokoe.html>.

TAJFEL, H (1982) 'Social Psychology of Intergroup Relations', Annual Review of Psychology, vol. 33, no. 1, pp. 1-39. [doi:://dx.doi.org/10.1146/annurev.ps.33.020182.000245]

TILLY, C (2004) 'Social Boundary Mechanisms', Philosophy of the Social Science, vol. 34, no. 2, pp. 211 -236. [doi:://dx.doi.org/10.1177/0048393103262551]

TILLY, C (2005) Identities, Boundaries, and Social Ties. Boulder: Paradigm.

VAN DER LAAN BOUMA-DOFF, W (2007) 'Confined Contact: Residential Segregation and Ethnic Bridges in the Netherlands', Urban Studies, vol. 44, no. 5-6, pp. 997-1017.

VAN EIJK, G (2010) Unequal networks. Spatial segregation, relationships and inequality in the city. Amsterdam: IOS Press.

VÖLKER, B and FLAP, H (2007) 'Sixteen Million Neighbors: A Multilevel Study of the Role of Neighbors in the Personal Networks of the Dutch', Urban Affairs Review, vol. 43, no. 2, pp. 256-284. [doi:://dx.doi.org/10.1177/1078087407302001]

WEBER, F (2001) 'Settings, Interactions and Things: A Plea for Multi-Integrative Ethnography', Ethnography, vol. 2, no. 4, pp. 475-499.

WELLMAN, B (2000) 'Changing Connectivity: A Future History of Y2.03K', Sociological Research Online, vol. 4, no. 4, <http://www.socresonline.org.uk/4/4/wellman.html>. 
WELLMAN, B and WORTLEY, S (1990) 'Different Strokes from Different Folks: Community Ties and Social Support', American Journal of Sociology, vol. 96, no. 3, pp. 558-588. [doi:://dx.doi.org/10.1086/229572]

WIMMER, A (2007) 'The Making and Unmaking of Ethnic Boundaries: A Multilevel Process Theory', American Journal of Sociology, vol. 113, no. 4, pp. 970-1022.

ZERUBAVEL, E (1996) 'Lumping and Splitting: Notes on Social Classification', Sociological Forum, vol. 11, no. 3, pp. 421-433. 